\title{
Adult, embryonic and fetal hemoglobin are expressed in human glioblastoma cells
}

\author{
MARWAN EMARA ${ }^{1,2}$, A. ROBERT TURNER ${ }^{1}$ and JOAN ALLALUNIS-TURNER ${ }^{1}$ \\ ${ }^{1}$ Department of Oncology, University of Alberta and Alberta Health Services, Cross Cancer Institute, Edmonton, AB T6G 1Z2, \\ Canada; ${ }^{2}$ Center for Aging and Associated Diseases, Zewail City of Science and Technology, Cairo, Egypt
}

Received September 7, 2013; Accepted October 7, 2013

DOI: 10.3892/ijo.2013.2186

\begin{abstract}
Hemoglobin is a hemoprotein, produced mainly in erythrocytes circulating in the blood. However, non-erythroid hemoglobins have been previously reported in other cell types including human and rodent neurons of embryonic and adult brain, but not astrocytes and oligodendrocytes. Human glioblastoma multiforme (GBM) is the most aggressive tumor among gliomas. However, despite extensive basic and clinical research studies on GBM cells, little is known about glial defence mechanisms that allow these cells to survive and resist various types of treatment. We have shown previously that the newest members of vertebrate globin family, neuroglobin ( $\mathrm{Ngb}$ ) and cytoglobin (Cygb), are expressed in human GBM cells. In this study, we sought to determine whether hemoglobin is also expressed in GBM cells. Conventional RT-PCR, DNA sequencing, western blot analysis, mass spectrometry and fluorescence microscopy were used to investigate globin expression in GBM cell lines (M006x, M059J, M059K, M010b, U87R and U87T) that have unique characteristics in terms of tumor invasion and response to radiotherapy and hypoxia. The data showed that $\alpha, \beta, \gamma, \delta, \zeta$ and $\varepsilon$ globins are expressed in all tested GBM cell lines. To our knowledge, we are the first to report expression of fetal, embryonic and adult hemoglobin in GBM cells under normal physiological conditions that may suggest an undefined function of those expressed hemoglobins. Together with our previous reports on globins (Ngb and Cygb) expression in GBM cells, the expression of different hemoglobins may constitute a part of series of active defence mechanisms supporting these cells to resist various types of treatments including chemotherapy and radiotherapy.
\end{abstract}

Correspondence to: Dr Marwan Emara, Department of Oncology, University of Alberta; and Alberta Health Services, Cross Cancer Institute, 11560 University Avenue, Edmonton, AB T6G 1Z2, Canada E-mail: memara@ualberta.ca

Key words: glioblastoma multiforme, hemoglobin, neuroglobin, cytoglobin

\section{Introduction}

Globins are hemo-containing proteins, have the ability to bind gaseous ligands [oxygen $\left(\mathrm{O}_{2}\right)$, nitric oxide $(\mathrm{NO})$ and carbon monoxide $(\mathrm{CO})]$ reversibly. They have been described in prokaryotes, fungi, plants and animals with an enormous diversity of structure and function (1). To date, hemoglobin, myoglobin, neuroglobin $(\mathrm{Ngb})$ and cytoglobin (Cygb) represent the vertebrate globin family with distinct function and tissue distributions (2). During ontogeny, developing erythro-

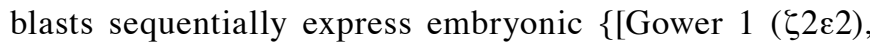
Gower $2(\alpha 2 \varepsilon 2)$, and Portland $1(\xi 2 \gamma 2)]$ to fetal [Hb F( $\left.\alpha 2 \gamma_{2}\right)$ ] and then adult [Hb A $(\alpha 2 \beta 2), 97 \%$; $\mathrm{Hb} \mathrm{A} 2(\alpha 2 \delta 2),<3 \%]\}$ hemoglobin (3). Adult hemoglobin, the most well studied globin in terms of structure, function and evolution (5), consists of two $\alpha$ and $\beta$ polypeptides globin chains (heterotetrameric protein) where each globin molecule contains a hydrophobic pocket that non-covalently binds an iron-protoporphyrin IX molecule (4).

In contradiction to previous thought, recently hemoglobin has been reported to be expressed not only in enucleated red cells, but also in other cell types. Hemoglobin expression has been reported in rodent brain (neurons of the cortex, hippocampus and cerebellum but not astrocytes and oligodendrocytes) (6); embryonic and adult mouse endometrium (7); alveolar epithelial type II cells of both rat (8) and human (9); and human breast cancer cells (10). Generally, vertebrate hemoglobin is known to function as a carrier protein of $\mathrm{O}_{2}$ and $\mathrm{CO}_{2}$ (9). However, recently hemoglobin has been reported to generate and transport $\mathrm{NO}$ or to scavenge $\mathrm{NO}$ and its metabolic derivatives $(11,12)$. As well as, other potential functions, including anti-oxidant and superoxide anion and $\mathrm{H}_{2} \mathrm{O}_{2}$ scavenging properties have been reported $(13,14)$.

Glioblastoma multiforme (GBM) is the most common and the most aggressive of astrocytic tumors, constituting $25 \%$ of all malignant nervous system tumors (15). Despite aggressive multimodality treatments, GBM is characterized by a very poor prognosis with median survival rate of about one year (16). The capability of GBM cells to infiltrate surrounding normal tissues (17), along with unidentified glial defence mechanisms due to expression of unknown protectant molecules, makes curative treatment by surgery, radiation and chemotherapies difficult, if not impossible.

We have previously reported that $\mathrm{Ngb}$ and $\mathrm{Cygb}$ are expressed in human GBM cell lines (18-20), as well as in human 
primary tumors including brain tumors (19). In this study, we examined whether hemoglobins $(\alpha, \beta, \gamma, \delta, \zeta$ and $\varepsilon)$ are also expressed in human GBM cell lines.

\section{Materials and methods}

Cell lines and in vitro culture conditions. The characterization and origin of the GBM cell lines have been published previously: the M059J (ATCC no. CRL2366, Manassas, VA, USA) is radio-sensitive and hypoxia-sensitive; M059K (ATCC no. CRL-2365) is radio-resistant and hypoxia-tolerant and M006x cell lines are hypoxia-tolerant (21-24). The U87T (tumor) and U87R (invasive) cell lines are established GBM cell lines (25) and were kindly provided by Dr Donna Senger (University of Calgary, Calgary, AB, Canada). All cells were maintained as monolayer cultures in DMEM/F12 media supplemented with $10 \%$ fetal calf serum and $1 \mathrm{mM}$ L-glutamine in a humidified atmosphere of $5 \% \mathrm{CO}_{2}$ in air at $37^{\circ} \mathrm{C}$. All tissue culture supplies were purchased from Gibco (Carlsbad, CA, USA).

RNA extraction and reverse transcription. RNeasy mini kit (Qiagen, Valencia, CA, USA) was used to isolate total RNA from GBM cultured cell lines. Reverse transcription (RT) was carried out with $0.1-1 \mu \mathrm{g}$ total RNA per $20 \mu \mathrm{l}$ reaction volume using QuantiTect reverse transcription kit (Qiagen).

Reverse transcription-PCR. Conventional RT-PCR was carried out with GeneAmp PCR system 9700 (Applied Biosystems, Foster City, CA, USA) using Platinum Pfx DNA polymerase (Invitrogen, Carlsbad, CA, USA) for 35 cycles. To detect $\alpha, \beta, \gamma, \delta, \zeta$ and $\varepsilon$ globin genes, specific oligonucleotide primer pairs (Table I) were designed using primer 3 plus program (26). For $\beta, \gamma$ and $\varepsilon$ globin genes, two primer pairs were designed to ensure their presence. For reaction specificity, different annealing temperatures were applied (Table I) where the annealing temperature for each set of primers was determined empirically by repeating the RT-PCR reaction at many different temperatures. Amplified RT-PCR products were separated in $2 \%$ agarose gel electrophoresis and visualized by ethidium bromide.

DNA sequencing. Bands of RT-PCR amplicons were excised from the agarose gel and purified using QIAEX II Gel Extraction Kit (Qiagen). Cycle sequencing protocol was carried out using BigDye ${ }^{\circledR}$ Terminator v3.1 (Applied Biosystems), BigDye Terminator v1.1 and v3.1 5X sequencing buffer (Applied Biosystems) and one of the primer pairs used in RT-PCR. The sequence reaction was cycled for 25 cycles $\left(96^{\circ} \mathrm{C}\right.$ for $1 \mathrm{~min}, 96^{\circ} \mathrm{C}$ for $10 \mathrm{sec}, 50^{\circ} \mathrm{C}$ for $5 \mathrm{sec}, 60^{\circ} \mathrm{C}$ for $4 \mathrm{~min}$, rapid thermal ramp to $4^{\circ} \mathrm{C}$ and hold) using thermal cycler. Sequencing reaction was precipitated (ethanol/EDTA), washed, dried out, resuspended in $10 \mu \mathrm{l}$ de-ionized formamide (injection buffer) and sequenced using (ABI PRISM ${ }^{\circledR} 310$ Genetic Analyzer, Applied Biosystems). Sequencing data were analysed by NCBI BLAST engine.

Western blot analysis. To detect globin proteins, M006x cells were washed four times with PBS. Whole-cell lysates were prepared using complete Lysis-M buffer (Roche Diagnostics, Indianapolis, IN, USA) and protein content determined using a protein assay kit (Pierce, Rockford, IL, USA). Equal amounts of protein $(50 \mu \mathrm{g})$ were resolved using Tris-Tricine-PAGE or 13\% SDS-PAGE under reducing condition and electro-transferred to polyvinylidene difluoride (PVDF) membranes (Bio-Rad Laboratories, Hercules, CA, USA). Membranes were blocked with $5 \%$ serum derived from the same animal species in which the secondary antibody is raised. Different primary antibodies were used in this study: 1:100 human anti-human hemoglobin monoclonal antibody (HCA042, AbD Serotec, Kidlington, UK); 1:100 goat anti-human hemoglobin ( $\alpha$ chain) polyclonal antibody (SC-31110, Santa Cruz Biotechnology Inc, Santa Cruz, CA); 1:100 mouse anti-human hemoglobin monoclonal antibodies, $\gamma$ chain (SC-21756) and $\beta$ chain (SC-21757, Santa Cruz Biotechnology); and 1:500 mouse anti-human hemoglobin ( $\varepsilon$ chain) monoclonal antibodies (10C-CR8008M1, Fitzgerald Industries International Inc, Concord, MA). Membranes were incubated with primary antibodies diluted in $5 \%$ serum for $2 \mathrm{~h}$. In consistent with the primary antibodies host species, different secondary antibodies conjugated with horseradish peroxidase were used: 1:1,000 goat anti-human IgG F(ab')2-polyclonal antibody (0500-0099, AbD Serotec); 1:6,000 goat anti-mouse IgG and 1:4,000 rabbit anti-goat polyclonal antibodies (DakoCytomation Denmark A/S, Glostrup, Denmark). Membranes were incubated with secondary antibodies diluted in 5\% serum for $1 \mathrm{~h}$. Bound proteins were detected using chemiluminescence reagents (SuperSignal West Pico Chemiluminescent Substrate, Thermo Scientific, Rockford, IL) and visualized by exposing to X-ray film (Fuji Photo Film, Tokyo, Japan) that was developed using a Kodak X-OMAT 2000A processor (Eastman Kodak Company, Tokyo, Japan).

Mass spectrometry and protein sequencing. M006x cells were lysed in complete Lysis-M buffer (Roche Diagnostics) and the protein content was determined using a protein assay kit (Pierce). Cellular lysates were incubated with the appropriate antibodies; goat anti-human hemoglobin ( $\alpha$ chain, SC-31110, and $\beta / \gamma / \delta / \varepsilon$ chain, SC-22718, Santa Cruz Biotechnology); polyclonal antibody, mouse anti-human $(\gamma$ chain, SC-21756, and $\beta$ chain, SC21757) hemoglobin monoclonal antibodies (Santa Cruz Biotechnology); and mouse anti-human hemoglobin [ $\varepsilon$ chain] monoclonal antibodies (10C-CR8008M1, Fitzgerald Industries International). Immunoprecipitation was carried out using an immunoprecipitation kit (Dynabeads Protein G, Invitrogen) according to manufacturer's instructions. Eluted proteins were reduced, heated and subjected to SDS-PAGE. The gel was stained (Bio-Safe Coomassie Stain, Bio-Rad) and the excised bands were analyzed by mass spectrometry at Institute of Biomolecular Design (IBD), University of Alberta (Edmonton, AB, Canada). In-gel tryptic digestion, peptide extraction and mass spectrometric analysis were done as described by Lopez-Campistrous et al (27) except that the ion trap mass spectrometry $\left(\mathrm{LCQ}^{\mathrm{TM}}\right.$ Deca XP ion trap mass spectrometer, Thermo Finnigan, San Jose, CA, USA) was used.

Immunofluorescence cell staining. Cultured cells were grown overnight on sterile coverslips. Cells were washed four times with PBS, fixed in cold methanol for $5 \mathrm{~min}$ and air dried for $15 \mathrm{~min}$. The cells were washed with three changes of PBS, 
Table I. Oligonucleotide primer pairs.

\begin{tabular}{|c|c|c|c|c|c|}
\hline $\begin{array}{l}\text { Globin } \\
\text { target } \\
\text { sequence }\end{array}$ & Forward primer $5^{\prime} \rightarrow 3^{\prime}$ & Reverse primer $5^{\prime} \rightarrow 3^{\prime}$ & $\begin{array}{c}\text { Annealing } \\
\text { temperature } \\
\left({ }^{\circ} \mathrm{C}\right)\end{array}$ & $\begin{array}{c}\text { PCR } \\
\text { product size } \\
\text { (bp) }\end{array}$ & $\begin{array}{c}\text { Lane number on } \\
\text { the agarose gel } \\
\text { (Fig. 1) }\end{array}$ \\
\hline Alpha & atgttcetgtccttccccaccaccaag & gcttaacggtatttggaggtcagcacg & 62 & 334 & 2 \\
\hline Beta & gtgaacgtggatgaagttggtggtgag & ttggacagcaagaaagcgagcttagtg & 54 & 411 & 3 \\
\hline Beta & tctgtccactcctgatgetg & tgctcaaggeccttcataat & 52 & 394 & 4 \\
\hline Gamma & acactcgcttctggaacgtc & gaattctttgccgaaatgga & 48 & 422 & 5 \\
\hline Gamma & gtggaagatgctggaggaga & gaattctttgccgaaatgga & 48 & 309 & 6 \\
\hline Delta & ctgggcagattactggtggt & ggcattgtgttcccaagttc & 44 & 440 & 8 \\
\hline Epsilon & gaatgtggaagaggctggag & atgtgcagaaggagggtgtc & 55 & 443 & 9 \\
\hline Epsilon & gcacatatctgcttccgaca & ccttgccaaagtgagtagcc & 55 & 421 & 10 \\
\hline Zeta & gaggaccatcattgtgtcca & gaattctttgccgaaatgga & 44 & 377 & 12 \\
\hline
\end{tabular}

Oligonucleotide primer pairs designed and synthesized for conventional RT-PCR and sequencing RT-PCR products. For $\beta, \gamma$ and $\varepsilon$ globin genes, two primer pairs were used to confirm their presence.

incubated with $10 \%$ normal serum (serum derived from the same animal species in which the secondary antibody is raised) for $30 \mathrm{~min}$ and then washed with PBS. Different primary antibodies were used; goat anti-human hemoglobin (1:75) polyclonal antibody ( $\alpha$ chain, SC-31110, Santa Cruz Biotechnology); mouse anti-human ( $\beta$ chain, SC21757) and ( $\gamma$ chain, SC-21756) hemoglobin (1:75) monoclonal antibodies (Santa Cruz Biotechnology) and mouse anti-human hemoglobin (1:250) monoclonal antibodies ( $\varepsilon$ chain, 10C-CR8008M1, Fitzgerald Industries International). Cells were incubated with primary antibody diluted in $1 \%$ serum for $1 \mathrm{~h}$. Different secondary antibodies were used [1:250 goat antimouse IgG polyclonal antibody Cy3 conjugated (610-704-124, Rockland Immunochemicals for Research, Gilbertsville, PA, USA); 1:250 donkey anti-goat IgG polyclonal antibody Alexa Flour 488 conjugated (A11055, Molecular Probes Inc., Eugene, OR, USA)]. Cells were washed three times with PBS and then incubated for $45 \mathrm{~min}$ with secondary antibody diluted in $1 \%$ serum. Cells were washed three with PBS (5 min each) and then the coverslips were mounted on slides with mounting media containing DAPI (ProLong Gold antifade reagent with DAPI, P36935, Invitrogen).

\section{Results}

Expression of $\alpha, \beta, \gamma, \delta, \zeta$ and $\varepsilon$ globin $m$ RNA in GBM cells in vitro. Amplified RT-PCR products separated on agarose gel revealed clear bands that coincide with their predicted sizes using different primer pairs (Fig. 1). Analysis of the DNA sequences extracted from the agarose bands using the NBCI BLAST engine revealed perfect alignments to their correspondents $\alpha, \beta, \gamma, \delta, \zeta$ and $\varepsilon$ globins mRNA in GenBank (Table II).

Expression of $\alpha, \beta, \gamma, \delta, \zeta$ and $\varepsilon$ globin proteins in $G B M$ cells in vitro. Western blot analyses of cell-lysate of M006x cells showed the presence of $\alpha, \beta, \gamma, \delta, \zeta$ and $\varepsilon$ globin protein (Fig. 2). As shown by others $(9,28)$ and as indicated in the

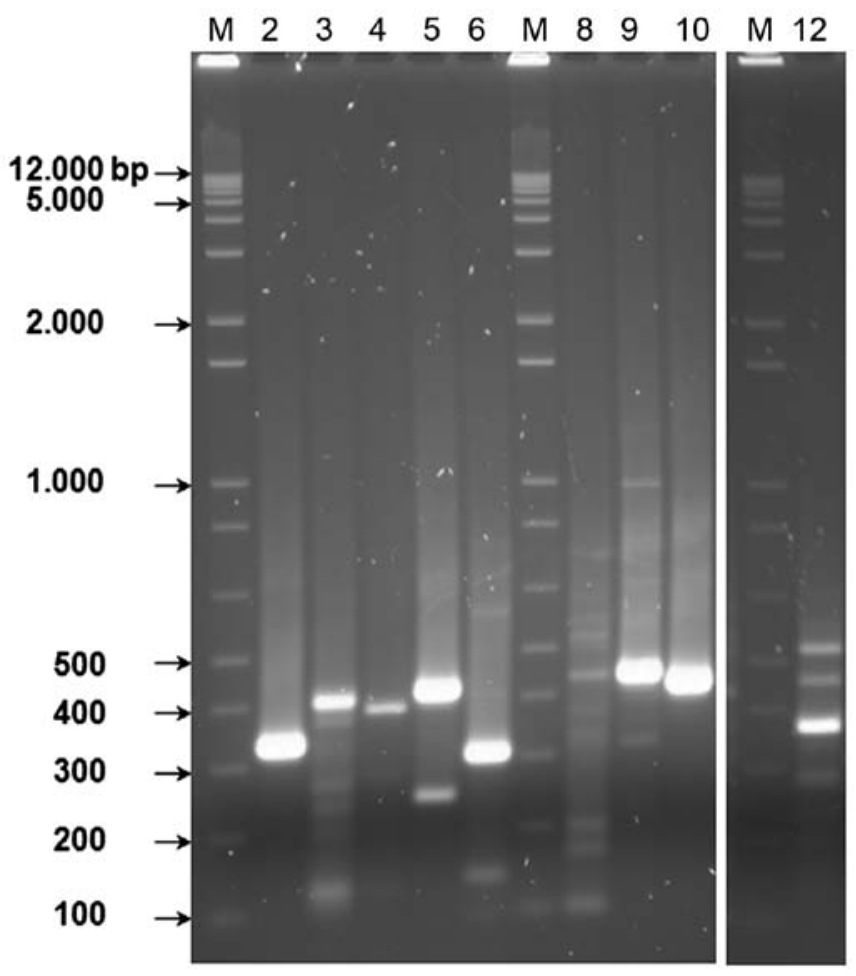

Figure 1. Globin genes expressed by M006x cells. Amplified RT-PCR products generated using designed sequence-specific primer pairs were separated on $2 \%$ agarose gel and visualized by ethedium bromide. The RT-PCR products [ $\alpha$ globin (lane 2); $\beta$ globin (lanes 3 and 4 ); $\gamma$ globin (lanes 5 and 6 ); $\delta$ globin (lane 8); $\varepsilon$ globin (lanes 9 and 10); $\zeta$ globin (lane 12)] of the predicted size (Table I) were further confirmed by sequencing. M, DNA ladder.

manufacturer's data sheet (AbD Serotec), adult hemoglobin and globins specific antibodies detected protein bands of 14, 26, $43 \mathrm{kDa}$ and higher in cell lysate and hemoglobin standard protein despite reduction and heat denaturing of the samples. The heterotetramer and globin dimer were more easily detected than monomer globins that require long exposure time accompanied by high background. Mass spectrometry 
Table II. DNA sequencing of RT-PCR amplicons.

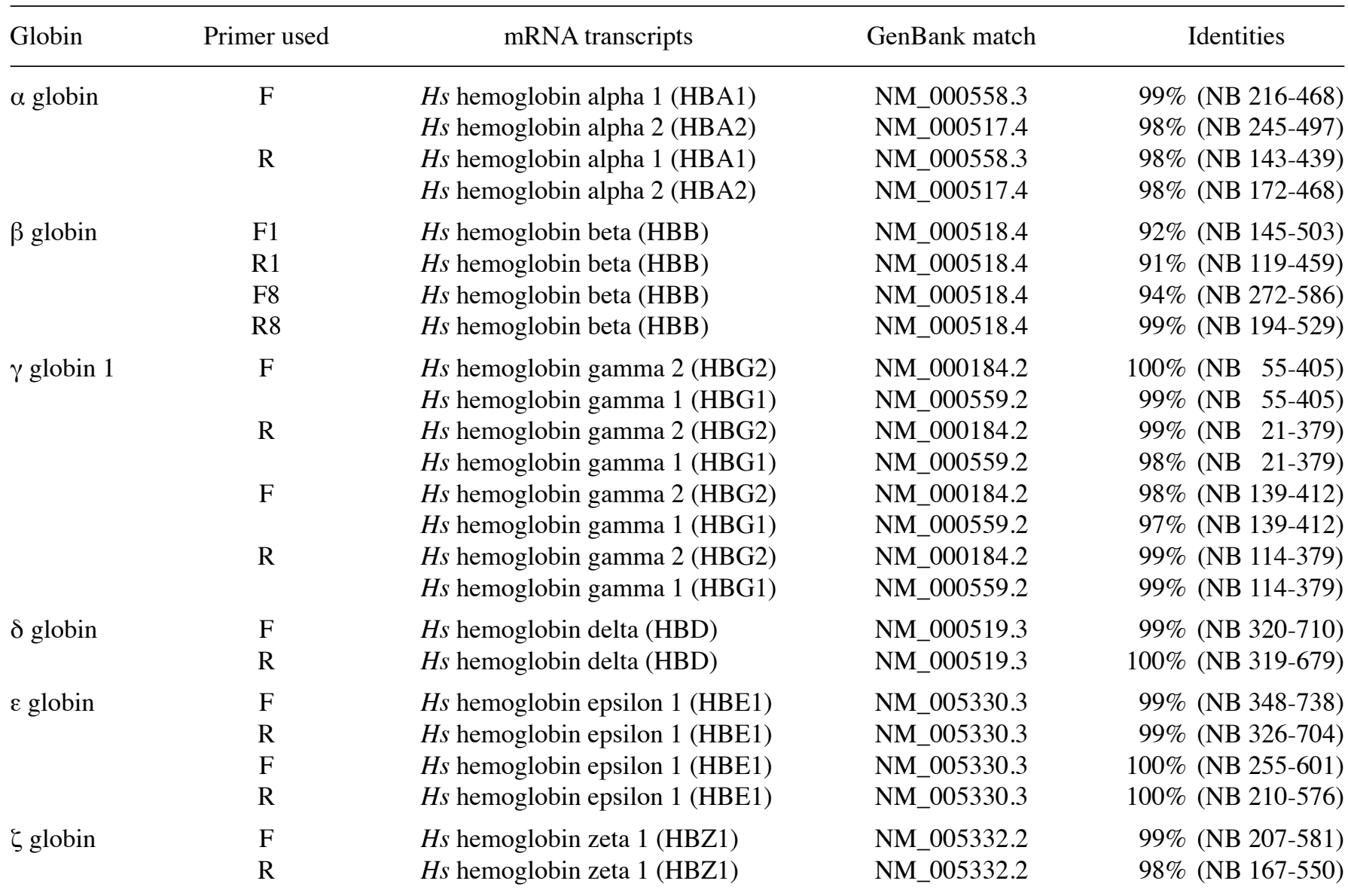

DNA bands of expected amplicon sizes were excised from the agarose gel and purified. Cycle sequencing was carried out with one of the primer pairs used in RT-PCR, precipitated, re-suspended in injection buffer and sequenced. Sequencing data was analysed using NCBI BLAST engine. F, forward; Hs, Homo sapiens; NB, nucleotide base; R, reverse.

Table III. Peptides of globin proteins identified by mass spectrometry.

\begin{tabular}{|c|c|c|c|c|}
\hline Accession no. & Protein hit & Matched peptides & $\begin{array}{l}\text { Ion } \\
\text { score }\end{array}$ & $\begin{array}{l}\text { Protein } \\
\text { score }^{\mathrm{a}}\end{array}$ \\
\hline gil229751 & $\begin{array}{l}\text { Chain } \alpha \text {, structure of haemoglobin } \\
\text { in the deoxy quaternary state with } \\
\text { ligand bound at the alpha haems } \\
\text { (Homo sapiens) }\end{array}$ & $\begin{array}{l}\text { VGAHAGEYGAEALER (pos. 17-31) } \\
\text { TYFPHFDLSHGSAQVK (pos. 41-56) } \\
\text { VADALTNAVAHVDDMPNALSALSDL } \\
\text { HAHK (pos. 62-90) }\end{array}$ & $\begin{array}{l}61 \\
45 \\
29\end{array}$ & 136 \\
\hline gil26892090 & $\begin{array}{l}\text { Beta globin chain variant } \\
\text { (Homo sapiens) }\end{array}$ & $\begin{array}{l}\text { SAVTALWGK (pos. 10-18) } \\
\text { VNVDEVGGEALGR (pos. 19-31) } \\
\text { GTFATLSELHCDK (pos. 84-96) } \\
\text { LLGNVLVCVLAHHFGK (pos. 106-121) } \\
\text { KFTPPVQAAYQK (pos.122-133) } \\
\text { VVAGVANALAHK (pos. 134-145) }\end{array}$ & $\begin{array}{l}39 \\
52 \\
50 \\
30 \\
61 \\
59\end{array}$ & 292 \\
\hline gil73762521 & $\begin{array}{l}\text { Delta globin Troodos variant } \\
\text { (Homo sapiens) }\end{array}$ & $\begin{array}{l}\text { VHLTPEEK (pos. 2-9) } \\
\text { LLGNVLVCVLACNFGK (pos. 106-121) } \\
\text { VVAGVANALAHK (pos. 134-145) }\end{array}$ & $\begin{array}{l}30 \\
38 \\
55\end{array}$ & 124 \\
\hline gil78099200 & $\begin{array}{l}\text { Hemoglobin subunit epsilon } \\
\text { Bradypus tridactylus }\end{array}$ & $\begin{array}{l}\text { LLVVYPWTQR (pos. 32-41) } \\
\text { LVGGVANALAHK (pos.134-145) }\end{array}$ & $\begin{array}{l}35 \\
45\end{array}$ & 80 \\
\hline
\end{tabular}




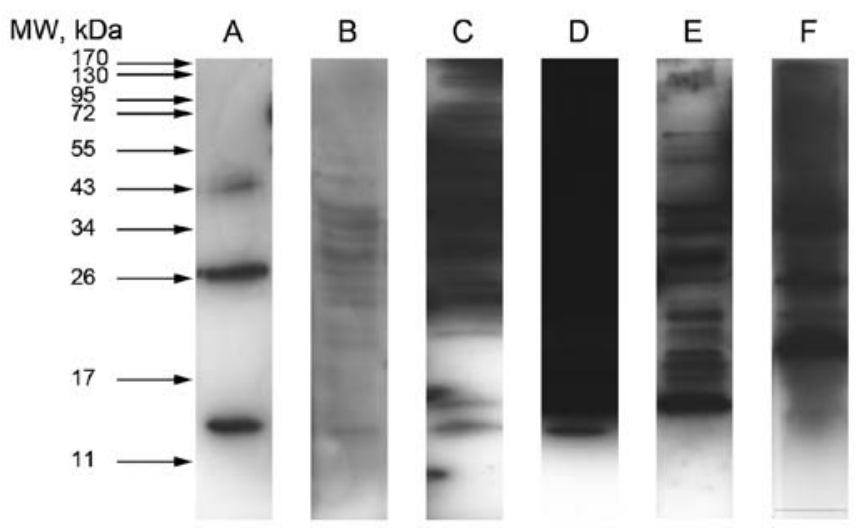

Figure 2. Western blot analyses of globin proteins expressed by M006x cell line. Cell lysate $(50 \mu \mathrm{g})$ was electrophoresed on $13 \%$ SDS-PAGE, electro-transferred to PVDF membrane and propped with anti-human antibody against (B) hemoglobin, (C) $\alpha$ globin, (D) $\beta$ globin, (E) $\gamma$ globin and (F) $\varepsilon$ globin. Blot A represents purified human hemoglobin propped with anti-human hemoglobin. analysis of different globin immunoprecipitates showed peptide match to $\alpha, \beta, \delta$, and $\varepsilon$ globin protein (Table III). The unsuccessful detection of $\gamma$ and $\zeta$ globin protein by mass spectrometry could be due to multiple factors including unsuitability of their relevant antibodies for the application of immunoprecipitation.

Immunofluorescence analysis. To confirm the expression of globin proteins, immunofluorescence experiments were carried out. Anti-human $\alpha, \beta, \gamma$ and $\varepsilon$ antibody incubated with fixed M006x cells that grown under aerobic conditions (Fig. 3) displayed both cytoplasmic and nuclear staining. This is consistent with the staining pattern of $\alpha, \beta$ globin previously observed in rat neurons $(6,28)$, murine and human A9 dopaminergic neurons, a subpopulation of cortical and hippocampal astrocytes, and in mature oligodentrocytes (29). Expression of $\alpha, \beta$ and $\varepsilon$ globin was higher in the cytoplasm whereas $\gamma$ globin was predominant in the nucleus.
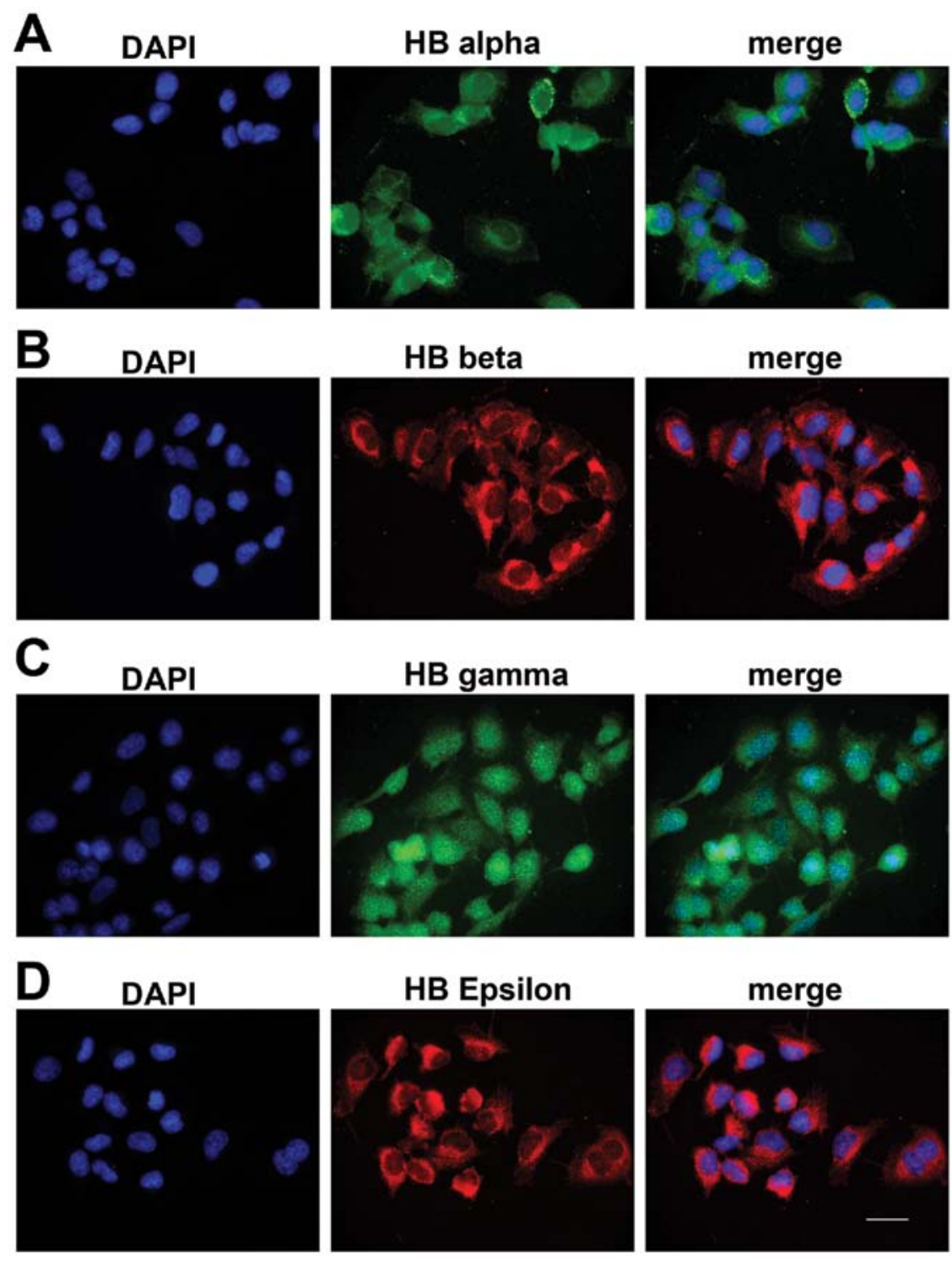

Figure 3. Immunofluorescence staining of $\alpha, \beta, \gamma$ and $\varepsilon$ globin in M006x cells cultured under aerobic conditions. Cytoplasmic staining of (A) $\alpha$, (B) $\beta$ and (D) $\varepsilon$ globin was higher than nuclear staining, whereas (C) $\gamma$ globin expression was higher in the nucleus than the cytoplasm. Nuclei were counterstained with DAPI nuclear staining (magnification, $\mathrm{x} 40$; scale bar, $100 \mu \mathrm{m})$. 


\section{Discussion}

We have previously reported that two newly discovered globins, neuroglobin and cytoglobin, are expressed in human primary GBM tumors and cell lines $(18,19)$. Here, using conventional RT-PCR and DNA sequencing, western blot analysis, immunofluorescence staining and mass spectrometry, we confirmed the presence of different hemoglobins $(\alpha, \beta, \gamma, \delta, \zeta$ and $\varepsilon)$ in GBM cells under normal physiological conditions. Others have reported $\alpha$ and $\beta$ globin expression in rodent neurons, but not in astrocytes and oligodendrocytes $(6,28)$, whereas Biagioli et al (29) reported their presence in A9 dopaminergic neurons, a subpopulation of cortical and hippocampal astrocytes and in mature oligodentrocytes. However, the heterogeneity of gliomas (30) and ability of gliobalstoma cell lines to co-express glial and neuronal markers (31) may partially explain the presence of neuroprotective globin molecules such as neuroglobin in GBM cells (18), as well as hemoglobin.

The most important functions of erythroid hemoglobin are the transport of $\mathrm{O}_{2}$ and $\mathrm{CO}_{2}(9)$, to bind $\mathrm{CO}$, and to scavenge and release NO (32). Anti-oxidative function of hemoglobin has been manifested by reducing production of hydrogen peroxide-induced intracellular radical oxygen species and enhancing cell viability after overexpression of the detected hemoglobin in rat mesangial cells (14). Moreover, human hemoglobin can detoxify highly oxidizing radicals yielding the respective non-toxic ferric states (33). Interestingly, hemoglobin was detected in breast cancer tissues and MCF7 cell line but not in normal breast tissue (10) suggesting a functional role for hemoglobin in carcinogenesis.

The expression of different types of hemoglobins $(\alpha, \beta$, $\gamma, \delta, \zeta$ and $\varepsilon$ ) representing fetal, embryonic and adult hemoglobin in GBM cells may imply an undefined potential role for these hemoglobins at different stages of cellular growth and adaptation, assisting those cells to resist aggressive multimodality treatments and consequently enabling cell survival. In addition, expression of the hemoglobins in all tested cell lines; M006x (hypoxia-tolerant) M059J (radiosensitive and hypoxia-sensitive), M059K (radio-resistant and hypoxia-tolerant) (21-24) U87T (tumor) and U87R (invasive) cell lines (25) may indicate that hemoglobin expression is not limited to GBM cells with certain cell characteristics but it is a common property of all tested cell lines.

Although $\alpha$ and $\beta$ globin expression has been reported in many non-erythroid cells, to our knowledge, we are the first to report the expression of $\alpha, \beta, \gamma, \delta, \zeta$ and $\varepsilon$ globins in human GBM cell lines under normal physiological conditions. Our results, together with the known non-oxygen transport related functions of hemoglobin suggest that hemoglobin expression in GBM cells may be a part of series of active defence and adaptation mechanisms by which these cells resist even aggressive multimodality treatments. Further experiments are required to investigate whether hemoglobin is upregulated under hypoxic conditions simulating hypoxic tumor microenvironment, and whether those hemoglobins are differentially regulated.

\section{Acknowledgements}

We thank Dr Richard Fahlman and Jack Moore for help with mass spectrometry, Dr Xuejun Sun for help with immuno- fluorescence imaging, and Bonnie Andrais for assistance with tissue culture. This study was supported by an award from the Canadian Cancer Society Research Institute with funds provided by the Canadian Cancer Society.

\section{References}

1. Hardison RC: A brief history of hemoglobins: plant, animal, protist, and bacteria. Proc Natl Acad Sci USA 93: 5675-5679, 1996.

2. Roesner A, Fuchs C, Hankeln T and Burmester T: A globin gene of ancient evolutionary origin in lower vertebrates: evidence for two distinct globin families in animals. Mol Biol Evol 22: 12-20, 2005.

3. Bunn HF and Forget BG: Hemoglobin: Molecular, Genetic, and Clinical Aspects. WB Saunders Co, Philadelphia, PA, 1986.

4. Hardison RC: Globin genes on the move. J Biol 7: 35, 2008.

5. Pesce A, Bolognesi M, Bocedi A, et al: Neuroglobin and cytoglobin. Fresh blood for the vertebrate globin family. EMBO Rep 3: 1146-1151, 2002.

6. Schelshorn DW, Schneider A, Kuschinsky W, et al: Expression of hemoglobin in rodent neurons. J Cereb Blood Flow Metab 29: 585-595, 2009

7. Dassen H, Kamps R, Punyadeera C, et al: Haemoglobin expression in human endometrium. Hum Reprod 23: 635-641, 2008.

8. Bhaskaran $\mathrm{M}$, Chen $\mathrm{H}$, Chen $\mathrm{Z}$ and Liu L: Hemoglobin is expressed in alveolar epithelial type II cells. Biochem Biophys Res Commun 333: 1348-1352, 2005.

9. Newton DA, Rao KM, Dluhy RA and Baatz JE: Hemoglobin is expressed by alveolar epithelial cells. J Biol Chem 281: 5668-5676, 2006.

10. Gorr TA, Wichmann D, Pilarsky C, et al: Old proteins - new locations: myoglobin, haemoglobin, neuroglobin and cytoglobin in solid tumours and cancer cells. Acta Physiol (Oxf) 202: 563-581, 2011.

11. Cosby K, Partovi KS, Crawford JH, et al: Nitrite reduction to nitric oxide by deoxyhemoglobin vasodilates the human circulation. Nat Med 9: 1498-1505, 2003.

12. Huang Z, Shiva S, Kim-Shapiro DB, et al: Enzymatic function of hemoglobin as a nitrite reductase that produces NO under allosteric control. J Clin Invest 115: 2099-2107, 2005.

13. Masuoka N, Kodama H, Abe T, Wang DH and Nakano T: Characterization of hydrogen peroxide removal reaction by hemoglobin in the presence of reduced pyridine nucleotides. Biochim Biophys Acta 1637: 46-54, 2003.

14. Nishi H, Inagi R, Kato H, et al: Hemoglobin is expressed by mesangial cells and reduces oxidant stress. J Am Soc Nephrol 19: 1500-1508, 2008.

15. Brandes AA, Tosoni A, Franceschi E, Reni M, Gatta G and Vecht C: Glioblastoma in adults. Crit Rev Oncol Hematol 67: 139-152, 2008.

16. Lim SK, Llaguno SR, McKay RM and Parada LF: Glioblastoma multiforme: a perspective on recent findings in human cancer and mouse models. BMB Rep 44: 158-164, 2011.

17. Alves TR, Lima FR, Kahn SA, et al: Glioblastoma cells: A heterogeneous and fatal tumor interacting with the parenchyma. Life Sci 89: 532-539, 2011.

18. Emara M, Salloum N and Allalunis-Turner J: Expression and hypoxic up-regulation of neuroglobin in human glioblastoma cells. Mol Oncol 3: 45-53, 2009.

19. Emara M, Turner AR and Allalunis-Turner J: Hypoxic regulation of cytoglobin and neuroglobin expression in human normal and tumor tissues. Cancer Cell Int 10: 33, 2010.

20. Fang J, Ma I and Allalunis-Turner J: Knockdown of cytoglobin expression sensitizes human glioma cells to radiation and oxidative stress. Radiat Res 176: 198-207, 2011.

21. Allalunis-Turner MJ, Barron GM, Day RS III, Dobler KD and Mirzayans R: Isolation of two cell lines from a human malignant glioma specimen differing in sensitivity to radiation and chemotherapeutic drugs. Radiat Res 134: 349-354, 1993.

22. Allalunis-Turner MJ, Barron GM, Day RS III, Fulton DS and Urtasun RC: Radiosensitivity testing of human primary brain tumor specimens. Int J Radiat Oncol Biol Phys 23: 339-343, 1992.

23. Allalunis-Turner MJ, Franko AJ and Parliament MB: Modulation of oxygen consumption rate and vascular endothelial growth factor mRNA expression in human malignant glioma cells by hypoxia. Br J Cancer 80: 104-109, 1999. 
24. Parliament MB, Allalunis-Turner MJ, Franko AJ, et al: Vascular endothelial growth factor expression is independent of hypoxia in human malignant glioma spheroids and tumours. Br J Cancer 82: 635-641, 2000.

25. Johnston AL, Lun X, Rahn JJ, et al: The p75 neurotrophin receptor is a central regulator of glioma invasion. PLoS Biol 5: e212, 2007.

26. Untergasser A, Nijveen H, Rao X, Bisseling T, Geurts R and Leunissen JA: Primer3Plus, an enhanced web interface to Primer3. Nucleic Acids Res 35: W71-W74, 2007.

27. Lopez-Campistrous A, Semchuk P, Burke L, et al: Localization, annotation, and comparison of the Escherichia coli $\mathrm{K}-12$ proteome under two states of growth. Mol Cell Proteomics 4: 1205-1209, 2005.

28. He Y, Hua Y, Liu W, Hu H, Keep RF and Xi G: Effects of cerebral ischemia on neuronal hemoglobin. J Cereb Blood Flow Metab 29: 596-605, 2009.
29. Biagioli M,Pinto M, Cesselli D, et al: Unexpected expression of alpha- and beta-globin in mesencephalic dopaminergic neurons and glial cells. Proc Natl Acad Sci USA 106: 15454-15459, 2009.

30. Valtz NL, Hayes TE, Norregaard T, Liu SM and McKay RD: An embryonic origin for medulloblastoma. New Biol 3: 364-371, 1991.

31. Rebetz J, Tian D, Persson A, et al: Glial progenitor-like phenotype in low-grade glioma and enhanced CD133-expression and neuronal lineage differentiation potential in high-grade glioma. PLoS One 3: e1936, 2008.

32. Schechter AN: Hemoglobin research and the origins of molecular medicine. Blood 112: 3927-3938, 2008

33. Goldstein S and Samuni A: Intra- and intermolecular oxidation of oxymyoglobin and oxyhemoglobin induced by hydroxyl and carbonate radicals. Free Radic Biol Med 39: 511-519, 2005. 